\title{
ANALYSIS OF TRAFFIC NOISE IN TWO CROSS-SECTIONS AT THE ROAD CROSSING THE CITY
}

\author{
Andrzej Bąkowski*, Leszek Radziszewski \\ Faculty of Mechatronics and Mechanical Engineering, Kielce University of Technology, Kielce, Poland \\ *E-mail of corresponding author: abakowski@tu.kielce.pl
}

\begin{abstract}
Resume
The paper presents an analysis of the noise recorded by the two road traffic noise-monitoring stations. The stations were located in Kielce, Poland, at the road No. 74: on the outskirts of the city and near the center. Based on the experimentally recorded data, an equivalent sound level and acoustic pressure were determined for three sub-intervals of the day: nights, days and evenings. The conducted analyses showed that the average annual values (depending only on the time sub-intervals) of the median do not differ significantly between stations. A similar conclusion can be drawn based on simulations of the median and the C90 percentile of the sound pressure . However, the maximum relative differences in the C99 percentile of the acoustic pressure between stations are around $13 \%$. The maximum relative differences in median pressure between stations are around 15\% (for the time sub-interval nights).
\end{abstract}

Available online: https://doi.org/10.26552/com.C.2021.1.B13-B21

\section{Article info}

Received 28 April 2020

Accepted 10 June 2020

Online 29 October 2020

\section{Keywords:}

urban traffic noise, monitoring station, variation of acoustic pressure

ISSN 1335-4205 (print version) ISSN 2585-7878 (online version)

\section{Introduction}

Short- or long-term noise indicators are used to assess the traffic noise, which significantly contributes to environmental pollution and greatly affects the comfort of life [1-2]. In order to monitor the noise and traffic volume of road vehicles, systems of stationary measuring stations operating throughout the year are being built in some cities [3-5]. Results of the noise monitoring are related to changes in the structure and volume of traffic in the city [6-7]. They also indicate the danger associated with the harmful effects of noise on the humans residing in specific areas of the city [8-9]. Kielce has more than ten such stations, installed both in the center and on the outskirts of the city. In this work, an analysis of the measurements results of the equivalent sound level, recorded by the two such stations, located at the large communication artery passing close to the city center, was carried out [10]. Kielce was chosen as an example of a medium-sized city (about 200,000 inhabitants), located in the southern part of central Poland. The temperature throughout the year varies from around $-5^{\circ} \mathrm{C}$ in January to around $+17^{\circ} \mathrm{C}$ in July. Average monthly precipitation is from $34 \mathrm{~mm}$ in October to $96 \mathrm{~mm}$ in July. The wind, predominantly from the south and west, reaches an average speed of about $3 \mathrm{~m} / \mathrm{s}$ over a year. Kielce gets on average 70 days of snow on the ground a year. Tests in Kielce on road No 74 showed that the permissible noise levels were exceeded, during the day - by $6 \mathrm{~dB}(\mathrm{~A})$, evenings - by $5 \mathrm{~dB}(\mathrm{~A})$, nights - by $11 \mathrm{~dB}(\mathrm{~A})$ [10]. Exceedances of applicable normative values are greatest at night. For that reason, the authors decided to conduct a detailed analysis of the road noise generated during this period.

\section{Noise monitoring stations}

The subject of research, presented in this work, are results of the equivalent sound level measurements recorded by stationary, automatic stations for monitoring noise and vehicle traffic located at Lodzka Rd. (marked as S1 station) and Jesionowa Rd. (marked as S2 station) in Kielce. The location of these stations in the urban layout of Kielce is shown in Figure 1. The distance between these stations is about $2 \mathrm{~km}$.

Streets Lodzka and Jesionowa form one communication route constituting a section of national road No. 74 from the western to eastern borders of the city. Lodzka Street consists of four lanes separated by a $3 \mathrm{~m}$ wide green belt. It is the main part of the exit route from the center of Kielce towards Lodz, Warsaw and Krakow. This road is mainly used for transit and suburban traffic. Jesionowa Street consists of five lanes separated by a $5 \mathrm{~m}$ wide green belt. It connects Lodzka street with the express road S74. It is intended for the urban and suburban traffic, as well as for transit traffic. These streets are at flat ground level and the technical condition of the bituminous surface is good. There are two large intersections with city roads between the measuring stations. The average daily traffic for S1 station is 20200 vehicles, including 2050 heavy and for S2 station 29500 vehicles, including 1900 heavy. During the night, 


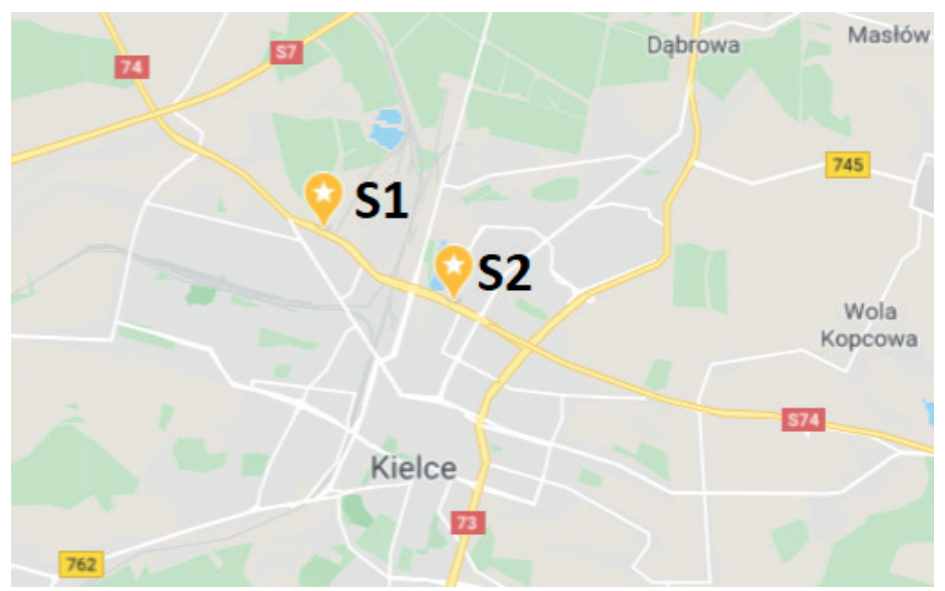

Figure 1 Location of the noise monitoring stations in Lodzka Rd (50.894369 and 20.611445) - station S1 and Jesionowa Rd (50.885759 and 20.636054) - station S2 in the urban layout of Kielce [after Google Maps]

the number of heavy vehicles registered by each station is similar and amounts to about 450 vehicles. For that time sub-interval, the ratio of light to heavy vehicle traffic is similar for both stations and is about 2:1 [11]. There is also a high railway embankment between the stations located transversely to the analyzed road section. Databases of the sound level measurement results were created in the form of calculated values of the equivalent sound level expressed in decibels. They cover the year 2013 with three time subintervals of a 24-hour interval: days, evenings and nights. Due to various technical problems, the databases are not complete. Analysis of data showed that in the period from 02-07-2013 to 28-08-2013 in the case of S1 station and from 02-05-2013 to 13-06-2013 in the case of the S2 station, the stations did not record an equivalent sound level. This increases the uncertainty of the measurement results. Monitoring stations in Kielce are installed on the roadside lighting poles, at a distance of about $20 \mathrm{~m}$ from intersections with city roads. The $\mathrm{S} 2$ station is located at the intersection with traffic lights. The acoustic measurements were carried out with the SVAN 958A, a four-channel digital vibration analyser and a class 1 sound level meter. A Microtech Gefell MK250 free-field, prepolarised 1/2" condenser microphone with a sensitivity of $50 \mathrm{mV} / \mathrm{Pa}$, and a SV 12L preamplifier with the frequency range from $3.5 \mathrm{~Hz}$ to $20 \mathrm{kHz}$ was used during the tests. The dynamic range is from $15 \mathrm{~dB}$ to $146 \mathrm{~dB}$. The device can operate in the temperature range from $-50^{\circ} \mathrm{C}$ to $100^{\circ} \mathrm{C}$ and it has a membrane made of nickel. The microphone for measuring sound pressure is located $4 \mathrm{~m}$ from the road edge at a height of $4 \mathrm{~m}$. The measurements were carried out 24 hours a day. The RMS values of the A sound level were registered in the buffer every $1 \mathrm{~s}$ and the results were recorded every 60 seconds. The data collected were the basis for equivalent sound level calculation for three time intervals, i.e., from 6:00 to 18:00, from 18:00 to 22:00 and from 22:00 to 6:00.

\section{$3 \quad$ Results analysis methods}

The most commonly used measure for noise assessment is the equivalent sound level $\left(L_{\text {Aeq, } T}\right)$ expressed in $\mathrm{dB}(\mathrm{A})$, defined as follows:

$$
\begin{aligned}
L_{\text {Aeq, } T} & =10 \cdot \log \left[\frac{1}{T} \int_{0}^{T}\left(\frac{p_{A}(t)}{p_{0}}\right)^{2} d t\right]= \\
& =10 \cdot \log \left[\left(\frac{p_{A_{R M S}}}{p_{0}}\right)^{2}\right],
\end{aligned}
$$

where:

$\mathrm{T}$ - measurement time, $\mathrm{s}$,

$p_{A}(t)$-sound pressure corrected by frequency characteristics $\mathrm{A}, \mathrm{Pa}$,

$p_{0}$ - the standardized reference acoustic pressure of $20.10^{-6} \mathrm{~Pa}$.

Expanded uncertainty of measurements is determined from [12]:

$u\left(t_{\alpha ; N-1}\right)=u= \pm \sqrt{\frac{\sigma^{2}}{N}+\frac{0.026 \sigma^{4}}{N-1}} t_{\alpha ; N-1}$,

where $t_{\alpha ; N-1}$ is the quantile of the $\mathrm{t}$ - distribution at the confidence level $\alpha$, standardized at 0.05 . Equation (2) can be applied, assuming that the null hypothesis about normal unimodal distributions $\left(\mathrm{H}_{0}\right)$ of the measured sound level, independent variables, adequately large quantity of data and low standard deviations, can be accepted. In the case of the traffic noise, those conditions are not always met.

The logarithm function used to represent $L_{\text {Aeq, }}$, determined according to Equation (1), may impede comparative analysis and affect results of the statistical tests. For that reason, the authors decided to additionally determine the RMS value of sound pressure (denoted $\left.p_{A_{R M S}}\right)$, from Equation (3), in the analyzed time interval $\mathrm{T}$ and use this parameter expressed in $\mathrm{mPa}$ for further analysis. 

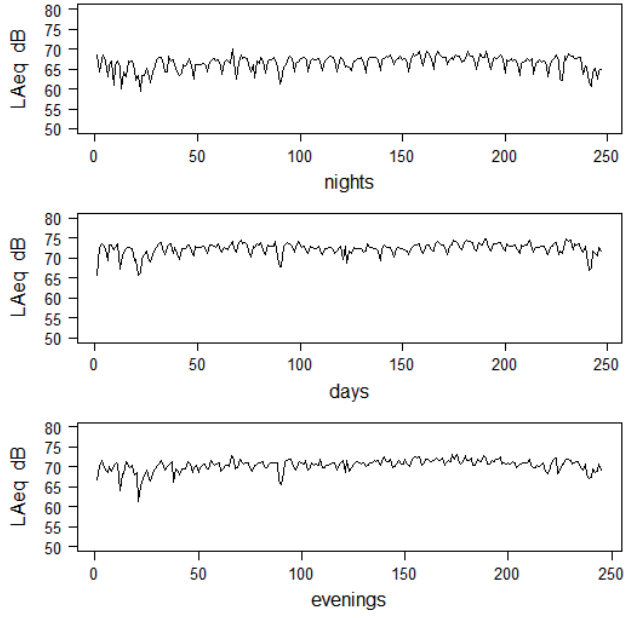

a)
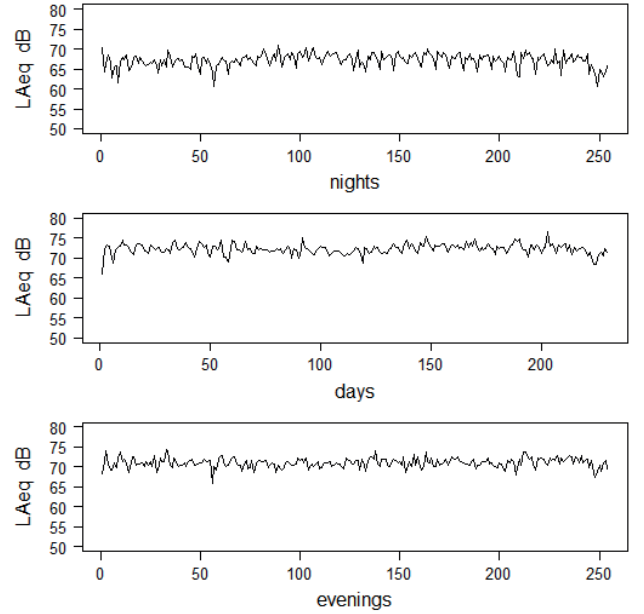

b)

Figure 2 Equivalent sound levels $L_{\text {Aeq, }}$ for all the measurement days in 2013 split into time sub-intervals; a) station $S 1$, b) station $S 2$ [10]

$p_{A R M S}=p_{A}=\sqrt{10^{(0.1 * L A e q, T)} \cdot p_{0}^{2}}$

The analysis carried out in these units allows easier comparison of the constant (expected value, median, percentiles e.g. $\mathrm{C}_{90}$ and $\mathrm{C}_{99}$ ) and variable (e.g. standard deviation, coefficient of variation of the standard deviation) components of the analyzed sound pressure signal. The study of the variable components contained in the analyzed signals was based on analysis of the classical and positional coefficients: standard deviation $\left(\sigma_{p_{A R M S}}\right)$, coefficient of variation of the standard deviation (denoted COV), positional coefficient of variation $\left(V_{Q 31}\right)$. In order to make it easier for the reader to evaluate the presented results, below are definitions of all the coefficients analyzed in this paper.

A frequently used measure for analyzing the variable component of sound pressure is the standard deviation, which can be referred to the expected value of the analyzed signal by obtaining the COV coefficient. The COV coefficient can be used to compare directly the variable components of the analyzed parameters. For the sound pressure, it can be expressed as:

$C O V_{p_{A R M S}}=C O V=$
$=\frac{\sqrt{\frac{1}{n-1} \sum_{i=1}^{i=n}\left(p_{A R M S i}-\overline{p_{A R M S}}\right)^{2}}}{\overline{p_{A R M S}}} \cdot 100 \%$.

Values of the classical coefficients of variation are strongly influenced by atypical data that was included in the analyzes. The impact of such data is smaller when using positional variability measures. The measure of dispersion of the analyzed variable is the average quartile deviation. Quartile deviation is an absolute measure that defines the average variance of half of the measurement data around the median after rejecting $25 \%$ data with the lowest values $Q_{1}\left(p_{A R M S}\right)$ and $25 \%$ data of the highest values $Q_{3}\left(p_{A R M S}\right)$ of the sound pressure. By relating it to the median, the positional coefficient of variation can be calculated as:
$V_{Q_{31}}=\frac{0.5 \cdot\left[Q_{3}\left(p_{A R M S}\right)-Q_{1}\left(p_{A R M S}\right)\right]}{M e d} \cdot 100 \%$.

Data that can be considered atypical have less impact on values of this coefficient. The relative differences between the positional statistical parameters, such as the $C_{X}$ and $C_{Y}$ percentiles, can be calculated according to the following relationship:

$\varepsilon_{X-Y}=\frac{C_{X}-C_{Y}}{C_{Y}} \cdot 100 \%$,

where:

$\varepsilon_{X-Y}$ - coefficient of relative difference between percentiles of order $\mathrm{X}$ and $\mathrm{Y}, \mathrm{X}>\mathrm{Y}$,

$C_{X}, C_{Y}$ - percentiles of order $\mathrm{X}$ and $\mathrm{Y}$, respectively.

This indicator can be used to analyze values of the noise parameters recorded by one measuring station. When analyzing data recorded by several measuring stations, the ratio of relative difference between the $\mathrm{X}$-percentiles can be calculated as follows:

$\varepsilon_{X}=\frac{C(S 2)_{X}-C(S 1)_{X}}{C(S 1)_{X}} \cdot 100 \%$,

where:

$C(S 2)_{X}, C(S 1)_{X}$ - percentiles of order $\mathrm{X}$ of the tested parameter determined for the stations $\mathrm{S} 1$ and $\mathrm{S} 2$, respectively.

\section{Measurements results}

Examples of diagrams showing recorded $L_{\text {Aeq, } T}$ for all the measurement days in 2013, split into 24-hour period sub-intervals, are shown in Figure 2a for station S1 and in Figure $2 \mathrm{~b}$ for station S2.

Table 1 shows basic average annual statistics of the parameter $L_{\text {Aeq, }}$ for the $24 \mathrm{~h}$ periods and three time sub-intervals determined from station $\mathrm{S} 1$ measurement data, expressed in $\mathrm{dB}(\mathrm{A})$. The Lilliefors and Shapiro- 

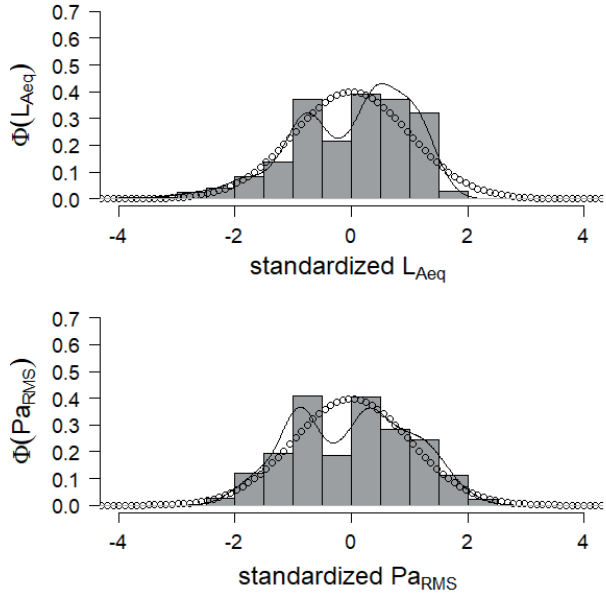

a)
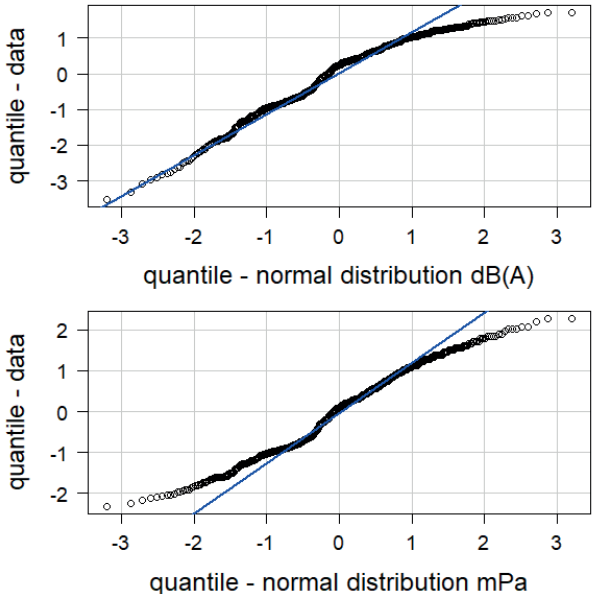

b)

Figure 3 Graphs prepared for standardized analyzed values of measurement data recorded by station S1, expressed in $\mathrm{dB}(\mathrm{A})$ or $\mathrm{mPa}$ a) histograms with the probability density function, $b$ ) $Q-Q$ quantile charts

Table 1 Average annual values of basic statistical noise measures determined by the station S1 and S2, for all the measurement days in 2013

\begin{tabular}{|c|c|c|c|c|c|c|c|c|c|c|}
\hline $\begin{array}{l}\text { period of } \\
\text { the day }\end{array}$ & $\begin{array}{c}\text { median } \\
L_{A e q, T} \\
\mathrm{~dB}(\mathrm{~A})\end{array}$ & $\begin{array}{c}u \\
\mathrm{~dB}(\mathrm{~A})\end{array}$ & $\begin{array}{c}\text { median } \\
p_{A R M S} \\
\mathrm{mPa}\end{array}$ & $\begin{array}{c}u_{\mathrm{A}} \\
\mathrm{mPa}\end{array}$ & $\begin{array}{c}\overline{p_{A R M S}} \\
\mathrm{mPa}\end{array}$ & $\begin{array}{c}\sigma_{p A_{R M S}} \\
\mathrm{mPa}\end{array}$ & $\begin{array}{c}\mathrm{COV} \\
\%\end{array}$ & $V_{Q_{31}} \%$ & $\begin{array}{c}\mathrm{C}_{90} \\
\mathrm{mPa}\end{array}$ & $\begin{array}{c}\mathrm{C}_{99} \\
\mathrm{mPa}\end{array}$ \\
\hline \multicolumn{11}{|c|}{ station S1 } \\
\hline $24 \mathrm{~h}$ & 70.50 & 0.24 & 66.99 & 0.73 & 64.68 & 19.93 & 30.82 & 24.72 & 91.42 & 104.50 \\
\hline night & 67.10 & 0.25 & 45.29 & 0.53 & 43.03 & 8.35 & 19.41 & 10.78 & 52.00 & 59.02 \\
\hline day & 72.70 & 0.20 & 86.30 & 0.84 & 83.77 & 13.18 & 15.73 & 9.53 & 98.41 & 107.51 \\
\hline evening & 70.70 & 0.20 & 68.55 & 0.66 & 67.24 & 10.30 & 15.32 & 9.02 & 79.26 & 88.89 \\
\hline \multicolumn{11}{|c|}{ station S2 } \\
\hline $24 \mathrm{~h}$ & 70.68 & 0.20 & 68.40 & 0.67 & 66.48 & 18.28 & 27.50 & 21.28 & 88.11 & 105.31 \\
\hline night & 67.43 & 0.22 & 47.05 & 0.54 & 46.34 & 8.56 & 18.47 & 12.17 & 56.43 & 64.89 \\
\hline day & 72.29 & 0.17 & 82.32 & 0.77 & 82.74 & 11.67 & 14.10 & 7.86 & 96.39 & 112.50 \\
\hline evening & 71.03 & 0.16 & 71.21 & 0.63 & 71.90 & 10.02 & 13.94 & 8.83 & 84.06 & 100.78 \\
\hline
\end{tabular}

Wilk statistical tests rejected hypothesis $\mathrm{H}_{0}$ because the calculated significance levels were lower than the required level of 0.05 . In the cases where the normal distribution of given data was doubtful, the Jarque-Bera test was additionally used. Results of those tests are not included in Table 1, but one can conclude that in the case of data expressed in $\mathrm{dB}(\mathrm{A})$ for the $\mathrm{S} 1$ and $\mathrm{S} 2$ station, in each of the four considered periods of the day, there are grounds to reject the $\mathrm{H}_{0}$ hypothesis. Figure 3 shows (for comparison) examples of histograms with the probability density function plotted and Q-Q quantile charts for standardized values of analyzed measurement data, expressed in $\mathrm{dB}(\mathrm{A})$ or $\mathrm{mPa}$.

Analysis of Figure 3 shows that, depending on the units used (i.e. $\mathrm{dB}(\mathrm{A})$ or $\mathrm{mPa}$ in which noise is expressed) one can notice differences in the shape of both histograms, probability density functions and Q-Q charts for standardized values of the analyzed data. The calculated values of kurtosis and skewness for data (expressed in $\mathrm{dB}(\mathrm{A})$ ) recorded by station $\mathrm{S} 1$ are 2.93 and -0.65 , respectively, which confirms the validity of rejection of the $\mathrm{H}_{0}$ hypothesis. Quantile charts are graphic illustrations of the fact that distributions of the analyzed data deviate from the normal distribution and that these distributions are left-skewed.

Statistical tests of the $L_{\text {Aeq,T }}$, determined from station $\mathrm{S} 1$ measurement data rejected the hypothesis $\mathrm{H}_{0}$ for all the average annual time intervals given in Table 1 , as in the case of analyzes for $\mathrm{S} 2$ stations. Values of the medians of the $L_{\text {Aeq,T, }}$, expressed in $\mathrm{dB}(\mathrm{A})$ for each time sub-interval presented in Table 1 are similar for both stations. The values of the medians of $L_{\text {Aeq, } T}$ for each time sub-interval, presented in Table 1, exceed values applicable in Poland in accordance with the law, especially for the time sub-interval night, i.e. by about $11 \mathrm{~dB}$.

Type A uncertainty of measurements of the traffic noise, calculated according to Equation (2), is about 0.2 $\mathrm{dB}(\mathrm{A})$.

Examples of diagrams, showing calculated according to Equation (3), split into 24-hour period sub-intervals, are 

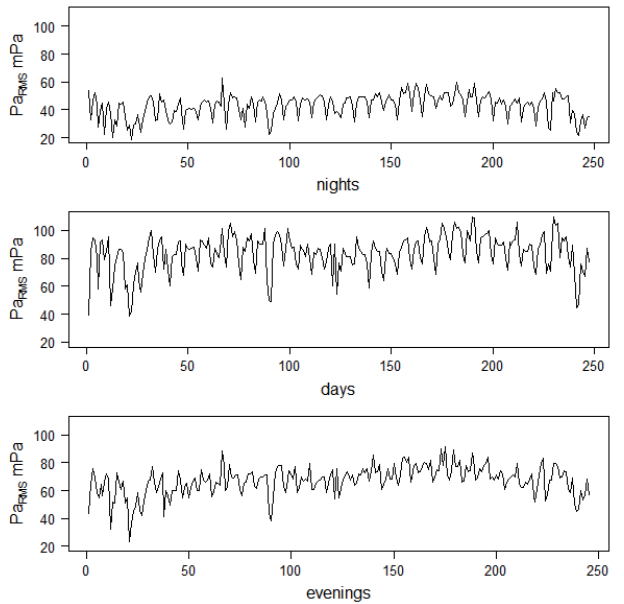

a)
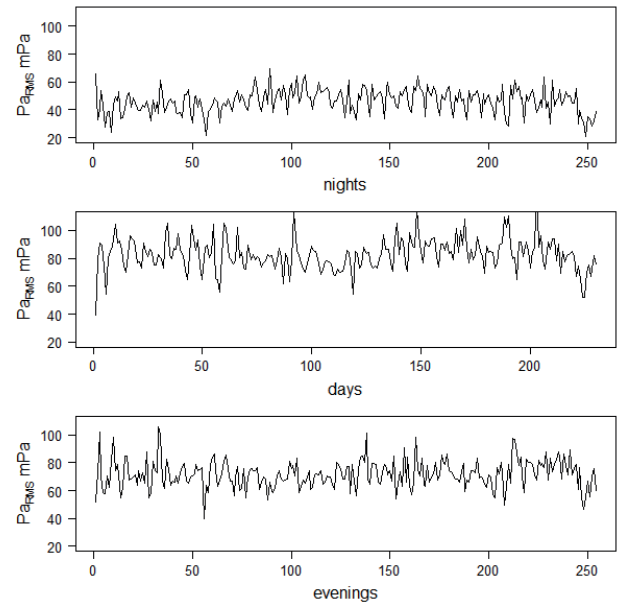

b)

Figure 4 Sound pressure values $p_{A R M S}$ expressed in mPa calculated for all the measurement days, split into time sub-intervals; a) S1 station, b) S2 station

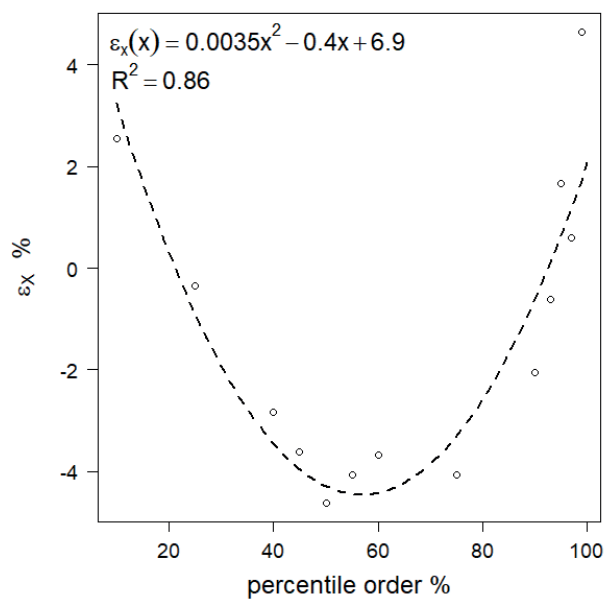

a)

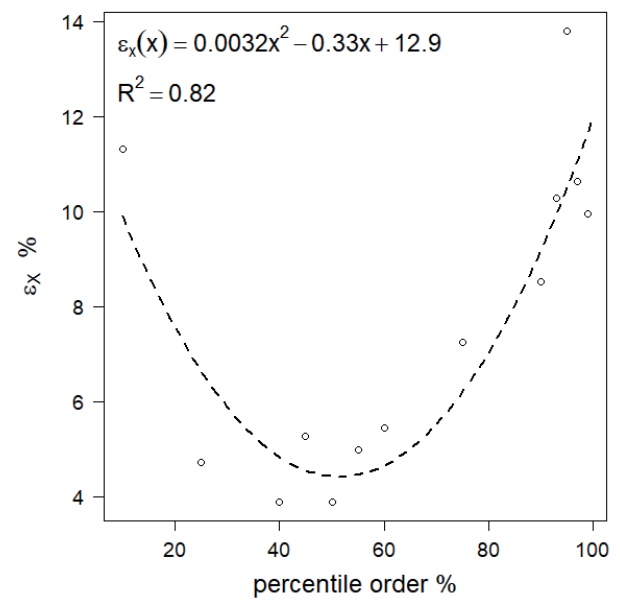

b)

Figure 5 The average annual values of the coefficient $\varepsilon_{X}$ of the relative difference in the sound pressure percentiles between the $S 1$ and $S 2$ stations, determined for the time sub-interval a) days, b) nights

presented in Figure 4a for station S1 and in Figure 4b for station S2.

Results of the statistical tests of acoustic pressure $p_{A R M S}$ allows concluding that only for the $\mathrm{S} 2$ station and for the time sub-interval nights - there are no grounds to reject the $\mathrm{H}_{0}$ hypothesis (at the significance level of 0.05). The pressure diagrams, presented in Figure 4, are varied both for each time sub-interval and for each monitoring station. These differences rely both on other values of constant and variable components of pressure and the nature of their changes, which is confirmed by values of the statistical parameters presented in Table 1 . For the $24 \mathrm{~h}$ periods, the median sound pressure for the $\mathrm{S} 1$ station is about $67 \mathrm{mPa}$ and for the S2 station about $68 \mathrm{mPa}$. Type A expanded uncertainty $\left(\mathrm{u}_{\mathrm{A}}\right)$ is about $1 \mathrm{mPa}$. Coefficients of variation of sound pressure for these periods and for both stations are in the range: for COV from $27.50 \%$ to $31 \%$ and for $V_{Q 31}$ from $21 \%$ to $25 \%$.

Depending on the time sub-interval, the median sound pressure for both stations assumes similar values, which are in the range for: nights from $45 \mathrm{mPa}$ to $47 \mathrm{mPa}$, days from $82 \mathrm{mPa}$ to $86 \mathrm{mPa}$ and evenings from $69 \mathrm{mPa}$ to 71 $\mathrm{mPa}$. However, the coefficients of variation of pressure for these time sub-intervals are in the following ranges: for $\mathrm{COV}$ - from $13 \%$ to $19 \%$, for $V_{Q 31}$ - from $8 \%$ to $12 \%$.

The calculated values of the $\mathrm{C}_{90}$ and $\mathrm{C}_{99}$ parameters of the noise pressure, determined for the $24 \mathrm{~h}$ periods, are similar for both stations and are approximately $90 \mathrm{mPa}$ and $105 \mathrm{mPa}$, respectively. The average annual coefficients of relative percentile differences of the order $X=99$ and $\mathrm{Y}=90$, calculated according to Equation (6), are always greater for the $\mathrm{S} 2$ station and their maximum value is about $\varepsilon_{99-90}(S 2)=20 \%$ - for the time sub-interval evenings. However, for the S1 station and for the time sub-interval evenings $\varepsilon_{99-90}(S 1)=12 \%$. The maximum value of the $\mathrm{C}_{99}$ parameter always occurs for the S2 station and for the time sub-interval days is about $112 \mathrm{mPa}$. The minimum value of the $\mathrm{C}_{99}$ parameter is for the $\mathrm{S} 1$ station and is about $59 \mathrm{mPa}$. Figure 5 presents the average annual values of the coefficient $\varepsilon_{X}$ (calculated according to Equation (7)) of the relative difference in pressure percentiles between stations S1 and S2. 

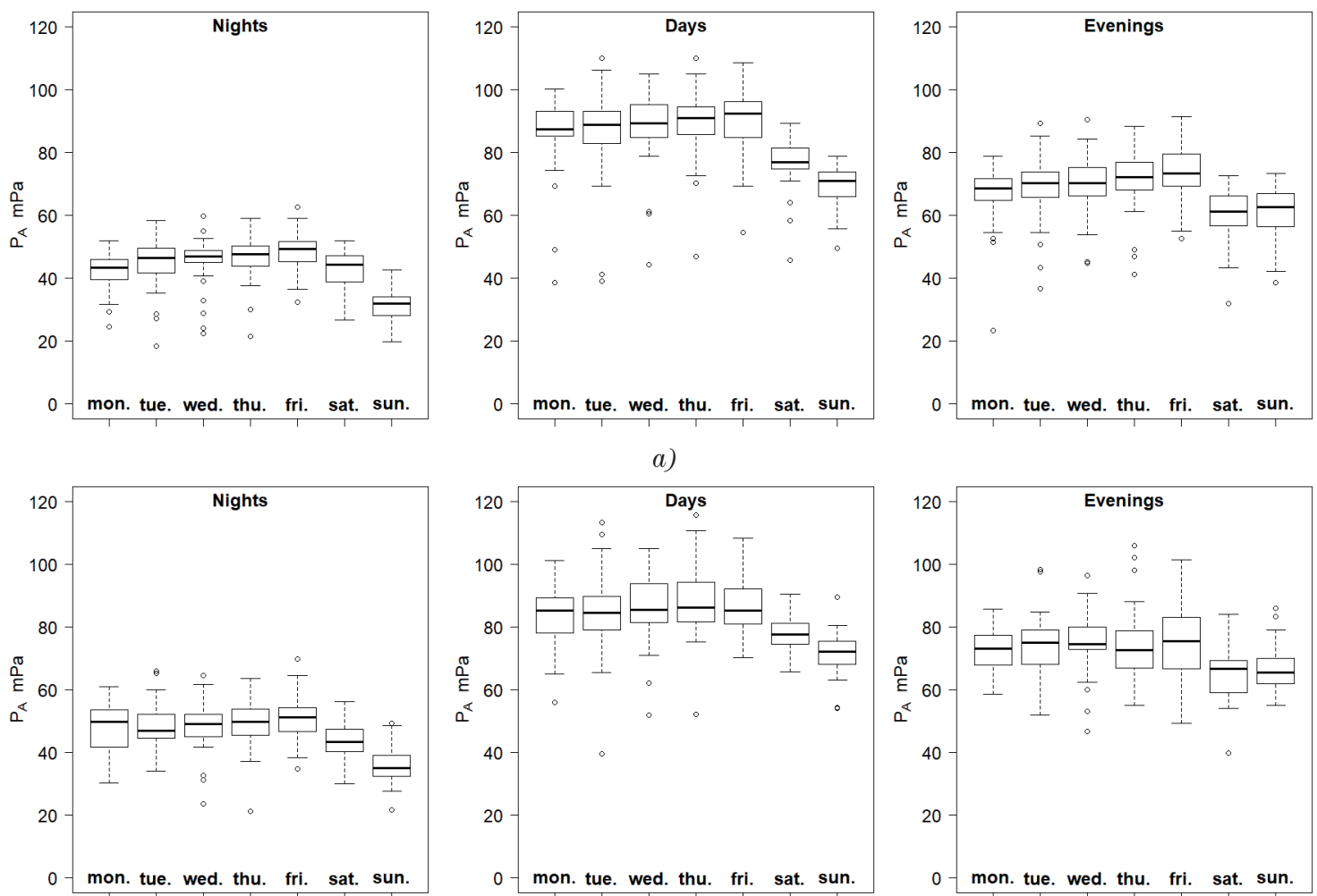

b)

Figure 6 Box plots of average annual sound pressure $p_{A R M S}$ for individual days of the week and for time sub-intervals: nights, days, evenings: a) S1 station, b) S2 station

The coefficient $\varepsilon_{X}$ takes both positive and negative values. A change in the sign of this factor indicates that some pressure percentiles for station S1 have higher values than for station S2 - this occurs especially for the time sub-interval days. Figure 5 shows that the minimum values occur near the 50 -th percentile. The variation range from minimum to maximum is around $10 \%$. The maximum value is around $\varepsilon_{99}=13 \%$ for the time sub-interval evenings. The analyzed relationships can be described by a second-degree polynomial. Values of the coefficients of this polynomial depend on the time sub-interval. Values of the correlation coefficients $\mathrm{R}$ are high and amount to about 0.80 . The analyzes conducted so far have not revealed significant large differences between the average annual values of a median and $\mathrm{C}_{90}$ noise pressure, determined for stations $\mathrm{S} 1$ and $\mathrm{S} 2$. However, for parameter $\mathrm{C}_{99}$ (for the evenings) the maximum relative pressure differences are around: $\varepsilon_{99}=13 \%$ (between stations S1 and S2), $\boldsymbol{\varepsilon}_{99-90}(S 1)=12 \%, \boldsymbol{\varepsilon}_{99-90}(S 2)=20 \%$. For any time subinterval, regardless of the station, the noise parameter values are higher than the normative ones. For the time sub-interval day - these differences are around $11 \mathrm{~dB}(\mathrm{~A})$.

In order to conduct further more detailed comparative analyzes of the two stations, it was decided to calculate the average annual values of the sound pressure parameters for individual days of the week [1]. Figure 6 presents box plots prepared for average annual pressures $p_{A_{R M S}}$ calculated for individual days of the week and for time sub-intervals: nights, days and evenings. These plots show how the median and the interval between the first and third quartiles change during the week. They also show that the set of data analyzed contains values that can be considered atypical. The only period when there is no unusual data is time sub-interval - nights - on Saturdays. Since no causes were identified for occurrence of the atypical data, these data were taken into account in further analysis of the recorded samples of the traffic noise. This phenomenon is thus characterized by high randomness, which is consistent with the findings reported in the literature [12].

These graphs show that changes in the median value on weekdays are different in nature depending on the economic function of the section of road being studied, i.e. location of the measuring station. At station S1, the median values increase gradually from Mondays to Fridays. At station S2, the median value increases slightly or decreases from Mondays to Fridays. However, on weekend days, for both stations, the nature of changes in median $p_{A R M S}$ is similar. On Saturdays and Sundays, the median value of $p_{\text {ARMS }}$ for time sub-interval nights and days decreases and for the evenings the differences are insignificant - even then, the permissible noise values are exceeded. The statistical tests for data expressed in $\mathrm{mPa}$ showed that for some of the weekdays and for certain time sub-intervals within a 24-hour period there was not enough evidence to reject the hypothesis $\mathrm{H}_{0}$. For the $\mathrm{S} 1$ and $\mathrm{S} 2$ stations, such days are Fridays, Saturdays and Sundays. Saturdays and Sundays are the weekend days and the traffic parameter values of road vehicles are different from on the business days.

As previous analyzes have shown, the largest exceedances of permissible noise occur for the time sub- 
Table 2 Average annual values of the statistical measures $p_{A_{R M S}}$ determined for individual days of the week for stations $S 1$ and S2, time sub-interval - nights

\begin{tabular}{|c|c|c|c|c|c|c|c|c|}
\hline days of the week & $\begin{array}{c}\text { median } \\
\mathrm{mPa}\end{array}$ & $\begin{array}{c}\overline{p_{A_{R M S}}} \\
\mathrm{mPa}\end{array}$ & $\begin{array}{c}\sigma_{p A R M S} \\
\mathrm{mPa}\end{array}$ & $\begin{array}{c}\mathrm{COV} \\
\%\end{array}$ & $\begin{array}{c}V_{Q_{31}} \\
\%\end{array}$ & $\begin{array}{c}\mathrm{C}_{90} \\
\mathrm{mPa}\end{array}$ & $\begin{array}{c}\mathrm{C}_{99} \\
\mathrm{mPa}\end{array}$ & $\mathrm{u}_{\mathrm{A}} \mathrm{mPa}$ \\
\hline \multicolumn{9}{|c|}{ station S1 } \\
\hline mondays & 43.25 & 41.84 & 6.28 & 15.00 & 7.41 & 46.88 & 52.00 & 1.06 \\
\hline tuesdays & 46.35 & 44.81 & 8.26 & 18.43 & 8.48 & 53.34 & 57.46 & 1.40 \\
\hline wednesdays & 46.88 & 45.32 & 7.80 & 17.20 & 4.03 & 51.41 & 58.14 & 1.32 \\
\hline thursdays & 47.70 & 46.28 & 6.69 & 14.46 & 6.50 & 52.30 & 56.78 & 1.12 \\
\hline fridays & 49.38 & 48.51 & 6.02 & 12.41 & 6.35 & 54.47 & 61.30 & 1.00 \\
\hline saturdays & 44.26 & 42.87 & 5.80 & 13.53 & 9.47 & 48.87 & 51.80 & 0.98 \\
\hline sundays & 32.06 & 31.35 & 5.07 & 16.18 & 9.47 & 37.46 & 42.10 & 0.86 \\
\hline \multicolumn{9}{|c|}{ station S2 } \\
\hline mondays & 49.78 & 48.24 & 7.94 & 16.46 & 11.98 & 58.00 & 61.00 & 1.34 \\
\hline tuesdays & 46.94 & 48.30 & 7.47 & 15.46 & 8.05 & 59.39 & 65.70 & 1.23 \\
\hline wednesdays & 48.98 & 48.33 & 8.08 & 16.71 & 7.04 & 56.74 & 63.48 & 1.35 \\
\hline wednesdays & 49.70 & 49.11 & 7.88 & 16.04 & 7.92 & 56.89 & 63.63 & 1.31 \\
\hline fridays & 51.13 & 50.65 & 6.95 & 13.72 & 7.47 & 56.90 & 67.86 & 1.13 \\
\hline saturdays & 43.30 & 43.34 & 5.95 & 13.73 & 8.32 & 50.50 & 55.79 & 0.99 \\
\hline sundays & 35.00 & 36.18 & 6.48 & 17.90 & 8.77 & 46.94 & 49.32 & 1.08 \\
\hline
\end{tabular}

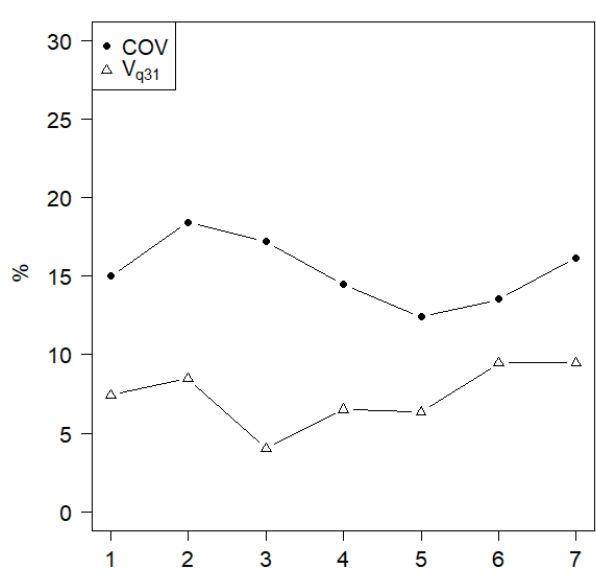

a)

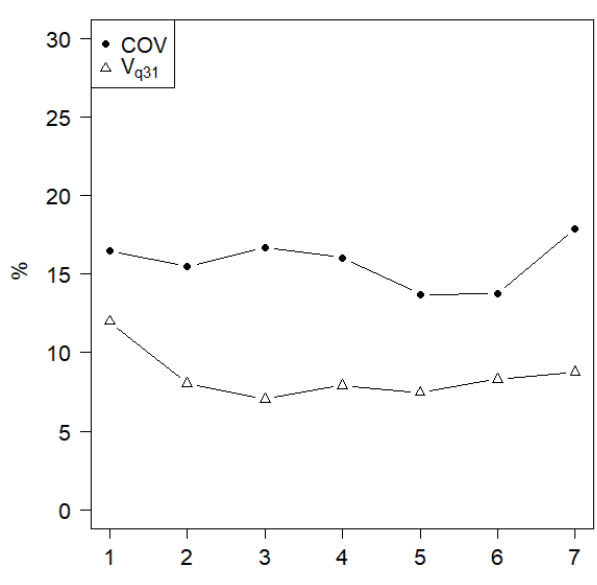

b)

Figure 7 Changes in the coefficient of variation of the sound pressure on particular days of the week for the time subinterval - nights a) S1 station, b) S2 station (designations; 1 - 7 - consecutive days of the week, from Monday to Sunday)

interval - nights, which is particularly burdensome for residents [13]. Therefore, the authors decided to conduct further analysis for nights and on individual days of the week. Some values of the noise parameters at night and for individual days of the week are given in Table 2.

Median $p_{A_{R M S}}$ is in the range: for the $\mathrm{S} 1$ station from $32 \mathrm{mPa}$ (on Sundays) to about $49 \mathrm{mPa}$ (on Fridays), for the $\mathrm{S} 2$ station from $35 \mathrm{mPa}$ (on Sundays) to $51 \mathrm{mPa}$ (on Fridays). Pressure percentiles $\mathrm{C}_{90}$ and $\mathrm{C}_{99}$ have the lowest values on Sundays: for the S1 station - $37 \mathrm{mPa}$ and 42 $\mathrm{mPa}$, respectively and for the $\mathrm{S} 2$ station $-47 \mathrm{mPa}$ and 49 $\mathrm{mPa}$, respectively. However, values of the largest pressure percentiles $\mathrm{C}_{90}$ and $\mathrm{C}_{99}$ are: for the $\mathrm{S} 1$ station on Fridays - 54 $\mathrm{mPa}$ and $61 \mathrm{mPa}$, respectively and for the $\mathrm{S} 2$ station on Tuesdays - $59 \mathrm{mPa}$ and on Fridays, $68 \mathrm{mPa}$.
The maximum relative differences between the values of parameters $\mathrm{C}_{90}$ and $\mathrm{C}_{99}$ for $\mathrm{S} 1$ station are $\varepsilon_{99-90}=13 \%$ (on Wednesdays) and for S2 station $\varepsilon_{99-90}=19 \%$ (on Fridays). The maximum relative differences in the $\mathrm{C}_{50}$, $\mathrm{C}_{90}$ or $\mathrm{C}_{99}$ parameter values between stations, regardless of the day of the week for the nights, are approximately: $\varepsilon_{50}=15 \%, \varepsilon_{90}=25 \%, \varepsilon_{99}=17 \%$.

Figure 7 shows the mutual relations between values of the coefficients of relative changes in the median pressure $p_{A R M S}$ on individual days of the week, for the nights for the stations S1 and S2. The COV coefficient values are several percent higher than the $V_{Q_{31}}$ coefficient. The nature of changes in their value during the week is varied for each station. For the S1 station, values of these coefficients increase from Mondays to Tuesdays and decrease from 
Tuesdays to Fridays, after which from Fridays to Sundays they increase again. On the other hand, for the S2 station, values of these ratios decrease from Mondays to Tuesdays, from Tuesdays to Fridays they decrease or increase, after which from Fridays to Sundays they increase again.

Analysis of Figure 7 shows that nature of changes in the COV values from Monday to Wednesday for each station is different. However, from Wednesday to Sunday, the nature of the changes is similar. In the case of the $V_{Q 31}$ coefficient values, the qualitative differences occur from Monday to Tuesday and from Tuesday to Sunday the nature of the changes is similar.

\section{Conclusions}

The study evaluated and compared results of measurements recorded by the two stationary road noisemonitoring stations, located on one road. For this purpose, the arithmetic mean and median, as well as the variable components of the signals tested were calculated. For analysis of these signals, the acoustic pressure $p_{A_{R M S}}$ and the classical $\mathrm{COV}$ and positional $V_{Q_{31}}$ coefficients of variation were used. Use of the relative difference coefficients between pressure percentiles $p_{A_{R M S}}$ has been proposed.

Annual average median and $\mathrm{C}_{90}$ percentile of the sound pressure $p_{A_{R M S}}$ (depending only on 24-hour subperiods) showed no significant differences between the $\mathrm{S} 1$ or $\mathrm{S} 2$ stations. For the $24 \mathrm{~h}$ periods the median, $\mathrm{C}_{90}$ and $\mathrm{C}_{99}$ percentile of the sound pressure $p_{A_{R M S}}$ for both stations S1 and S2 are similar and are about $67 \mathrm{mPa}, 90$ $\mathrm{mPa}$ and $105 \mathrm{mPa}$, respectively. However, for both stations, depending on the time sub-interval, the median pressure $p_{A R M S}$ assume similar values, which are around: for nights $46 \mathrm{mPa}$, for days from $84 \mathrm{mPa}$ and for evenings 70 $\mathrm{mPa}$. The maximum values of the $\mathrm{C}_{99}$ parameter are always present for the $\mathrm{S} 2$ station and for the time sub-interval days are about $112 \mathrm{mPa}$. The minimum value of the $\mathrm{C}_{99}$ parameter is for the $\mathrm{S} 1$ station and is about $59 \mathrm{mPa}$. At any time sub-interval, regardless of the monitoring station, values of the noise parameters are higher than normative. For the night, these differences are the largest and amount to about $11 \mathrm{~dB}(\mathrm{~A})$. The relative differences between the $\mathrm{C}_{90}$ and $\mathrm{C}_{99}$ parameter values are always greater for the S2 stations and their maximum value is approximately $\varepsilon_{X-Y}(S 2)=20 \%$ - for the evenings. However, for the S1 station and for the evenings $\varepsilon_{X-Y}(S 1)=12 \%$. The maximum relative differences in $\mathrm{C}_{99}$ percentile pressure between the stations S1 and S2 are approximately 13\% for the evenings. Pressure variation coefficients for the $24 \mathrm{~h}$ periods and for both stations are in the range: for the COV from $27.50 \%$ to $31 \%$ and for $V_{Q_{31}}$ from $21 \%$ to $25 \%$. Whereas the coefficients of pressure variation for: nights, days, evenings are in the range: for COV from $13 \%$ to $19 \%$, for $V_{Q_{31}}$ from $8 \%$ to $12 \%$.

In order to conduct more detailed comparative noise analyzes for the stations tested, the average annual values of the sound pressure parameters on particular days of the week were calculated. At station S1, the median values increase gradually from Mondays to Fridays. At S2, the median value increases slightly or decreases from Mondays to Fridays. This nature of the median value changes on weekdays is due to location of the measuring stations. However, at weekends, the nature of changes in median $p_{A R M S}$ is similar for both stations.

As previous analyzes for the time sub-interval night have shown: the structure of vehicle traffic for both stations is similar and the largest exceedances of permissible noise occur. It has been shown that at nights for stations $\mathrm{S} 1$ and S2: the minimum median $p_{A_{R M S}}$ occur on Sundays and the maximum on Fridays. Percentile $\mathrm{C}_{90}$ and $\mathrm{C}_{99}$ for station $\mathrm{S} 1$ have the lowest values on Sundays and the highest on Fridays. Whereas for $\mathrm{S} 2$ station $-\mathrm{C}_{90}$ and $\mathrm{C}_{99}$ percentiles have the smallest values on Sundays and the highest ones on Tuesdays and Fridays, respectively. The maximum relative differences between the $\mathrm{C}_{90}$ and $\mathrm{C}_{99}$ percentiles for the S1 station are $\varepsilon_{99-90}=13 \%$ (on Wednesdays, nights) and for the S2 station $\varepsilon_{99-90}=19 \%$ (on Fridays, nights). The maximum relative differences in the $\mathrm{C}_{50}, \mathrm{C}_{90}$ or $\mathrm{C}_{99}$ percentiles between stations, regardless of the day for the nights, are approximately: $\varepsilon_{50}=15 \%, \varepsilon_{90}=25 \%$, $\varepsilon_{99}=17 \%$. It should be noted that the median values of $p_{A R M S}$ for both stations are in ranges with similar boundaries and a span of about $16 \mathrm{mPa}$. On the other hand, for parameter $\mathrm{C}_{99}$, the differences between the lower boundaries of the ranges are $7 \mathrm{mPa}$ and the values of the lower and upper boundaries for each station differ by 19 $\mathrm{mPa}$ (for nights).

Minimal values of the coefficients of variation for the time sub-interval night occur on different days: for $V_{Q_{31}}$ on Wednesdays and for COV on Fridays. The nature of the change in COV value from Mondays to Wednesdays for each station is different. However, from Wednesdays to Sundays, the nature of the changes is similar. In the case of the $V_{Q_{31}}$ coefficient value, qualitative differences occur from Mondays to Tuesdays and from Tuesdays to Sundays, the nature of the changes is similar.

\section{References}

[1] GERAGHTY, D., O'MAHONY, M. Investigating the temporal variability of noise in an urban environment. International Journal of Sustainable Built Environment [online]. 2016, 5(1), p. 34-45. ISSN 2212-6090. Available from: https://doi.org/10.1016/j.jjsbe.2016.01.002 
[2] KHAIWAL, R., SINGH, T., TRIPATHY, J. P., MOR, S., MUNJAL, S., PATRO, B., PANDA, N. Assessment of noise pollution in and around a sensitive zone in North India and its non-auditory impacts. Science of the Total Environment [online]. 2016, 566-567, p. 981-987. ISSN 0048-9697. Available from: https://doi.org/10.1016/j.scitotenv.2016.05.070

[3] VOGIATZIS, K., REMY, N. Environmental noise mapping as a smart urban tool development. In: Smart Urban Development [online]. IntechOpen, 2019. Available from: https://doi.org/10.5772/intechopen.88449

[4] CZYZEWSKI, A., KOTUS, J., SZCZODRAK, M. Online urban acoustic noise monitoring system. Noise Control Engineering Journal [online]. 2012, 60(1), p. 69-84. ISSN 0736-2501. Available from: https://doi.org/10.3397/1.3670102

[5] MIHAJLOV, D. I., PRASCEVIC, M. R. Permanent and semi-permanent road traffic noise monitoring in the city of Nis (Serbia). Journal of Low Frequency Noise, Vibration and Active Control [online]. 2015, 34(3), p. 251-268. ISSN 1461-3484, eISSN 2048-4046. Available from: https://doi.org/10.1260/0263-0923.34.3.251

[6] PETROVA, M., NENKO, A. Urban emptiness as a resource for sustainable urban development. Management of Environmental Quality: An International Journal [online]. 2018, 29(3), p. 388-405. ISSN 1477-7835. Available from: https://doi.org/10.1108/MEQ-01-2018-0004

[7] FIGLUS, T., GNAP, J., SKRUCANY, T., SZAFRANIEC, P. Analysis of the influence of different means of transport on the level of traffic noise. Scientific Journal of Silesian University of Technology. Series Transport [online]. 2017, 97, p. 27-38. ISSN 0209-3324, eISSN 2450-1549. Available from: https://doi.org/10.20858/sjsutst.2017.97.3

[8] BASNER, M., MCGUIRE, S. WHO environmental noise guidelines for the European region: a systematic review on environmental noise and effects on sleep. International Journal of Environmental Research and Public Health [online]. 2018, 15(3), p. 519. eISSN 1660-4601. Available from: https://doi.org/10.3390/ijerph15030519

[9] JANDACKA, D., DECKY, M., DURCANSKA, D. Traffic related pollutants and noise emissions in the vicinity of different types of urban crossroads. In: IOP Conference Series: Materials Science and Engineering: proceedings. IOP Publishing, 2019. p. 012152.

[10] BAKOWSKI, A., RADZISZEWSKI, L., DEKYS, V. Urban noise recorded by stationary monitoring stations. In: IOP Conference Series: Materials Science and Engineering: proceedings. Vol. 245. Iss. 4. IOP Publishing, 2017. p. 042045. Available from: https://doi.org/10.1088/1757-899X/245/4/042045

[11] BOCHATKIEWICZ, J. Acoustic maps of the city of Kielce - updated 2013 / Mapy akustyczne miasta Kielce aktualizacja 2013 (in Polish) [online]. Available from: http://www.um.kielce.pl/gfx/kielce2/userfiles/files/srodowisko/ opracowania/mapa_akustyczna_aktualizacja_2013.pdf

[12] PRZYSUCHA, B., BATKO, W., SZELAG, A. Analysis of the accuracy of uncertainty noise measurement. Archives of Acoustics [online]. 2015, 40(2), p. 183-189. ISSN 0137-5075, eISSN 2300-262X. Available from: https://doi.org/10.1515/ aoa-2015-0020

[13] SLAVIK, R., GNAP, J. Selected problems of night-time distribution of goods within city logistics. Transportation Research Procedia [online]. 2019, 40, p. 497-504. ISSN 2352-1465. Available from: https://doi.org/10.1016/j.trpro.2019.07.072 